\title{
20
}

\section{Development and Use of Continuous SWMM for CSO Notification for the City of Detroit}

Philip Brink, Andrew Santini, Amal Ibrahim and Mark TenBroek

The City of Detroit has 77 combined sewer overflow (CSO) outfalls within its sewer collection system. The City's National Pollutant Discharge Elimination System (NPDES) permit for these outfalls mandates that the public must be notified of any CSO events. The notification method developed for the City uses a continuous SWMM model for determining the occurrence and time of overflow. These results are submitted to the state agency for compliance with the state regulatory requirements. This notification method was approved by the state as an interim reporting method until an instrumentation project currently under way is completed.

\subsection{Introduction}

A schematic of the greater Detroit regional sewer system's tributary area is shown in Figure 20.1. The shadings in the schematic represent various sewer districts within the system. The regional system serves 250 square miles (646 $\left.\mathrm{km}^{2}\right)$ of combined sewers and 630 square miles $\left(1628 \mathrm{~km}^{2}\right)$ of separate sewers. The regional system includes over 140 combined sewer overflow (CSO) outfalls. The City of Detroit has 77 outfalls within its portion of the regional sewer collection system.

Brink, P., A. Santini, A. Ibrahim and M.J. TenBroek. 2001. "Development and Use of Continuous SWMM for CSO Notification for the City of Detroit." Journal of Water Management Modeling R207-20. doi: 10.14796/JWMM.R207-20.

(C) CHI 2001 www.chijournal.org ISSN: 2292-6062 (Formerly in Models and applications to Urban Water Systems. ISBN: 0-9683681-4-X) 


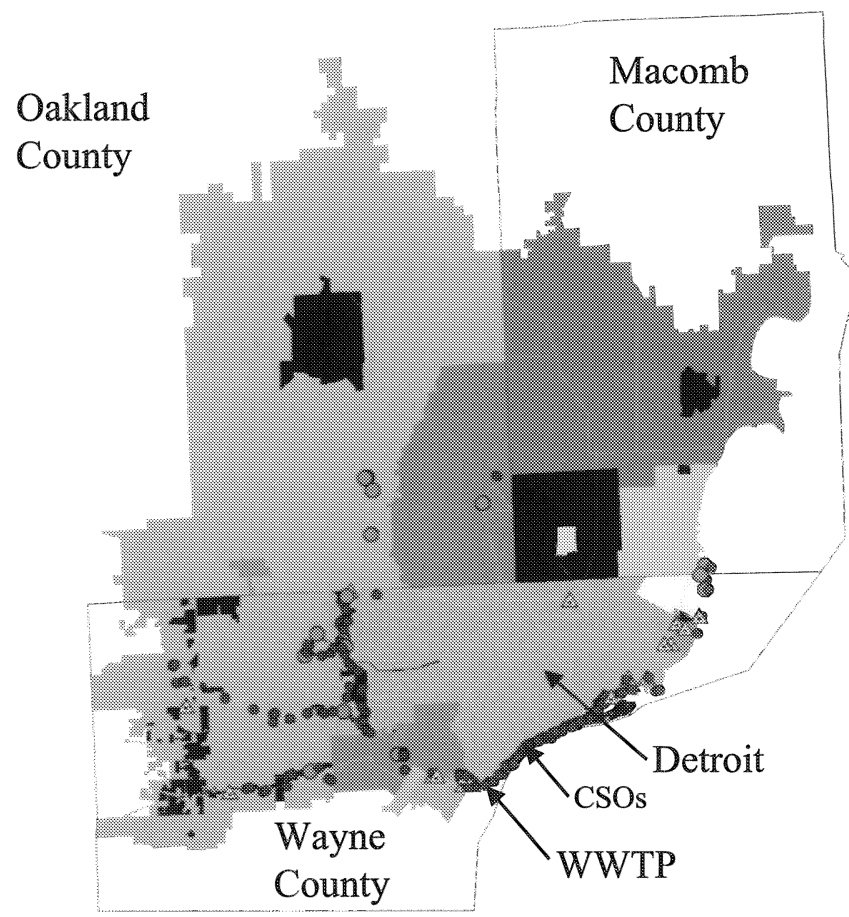

Figure 20.1 Greater Detroit regional sewer system service area.

The city has a National Pollutant Discharge Elimination System (NPDES) permit for these outfalls (NPDES Permit No. MI0022802, Part I, Section A.9). One of the requirements of this permit is that the public must be notified of any combined sewer discharges from the city's combined collection system.

In cases where pumping stations or CSO basins are used to discharge these flows to the receiving waters, it is understood that the approximate time, volume, and duration of the overflow can be calculated based on pumping records. At regulated overflow sites, all of which are unmetered, operators do not normally take any actions that result in the discharge of combined sewage. Since these overflows take place automatically, the overflows that result are simply a consequence of flows to the interceptor sewers exceeding the capacity of these sewers. In these cases, information on time, volume and duration of overflows is not available.

Of the 77 overflow relief sites located within Detroit, only six are pumped overflows; the rest are automatic regulated overflow sites. Detroit Water and Sewerage Department (DWSD) has a project currently underway to install instrumentation at each outfall to determine overflow in real time. In the meantime, as information on volume and duration of overflows currently is not 
available at these sites, an alternative method for estimating these overflows was needed to comply with the NPDES permit requirement. This chapter describes the development and use of a CSO Notification Model as an interim method to comply with requirements of this regulation until instrumentation of each outfall can be implemented.

\subsection{CSO Notification Background}

In 1972, the U.S. government passed the Clean Water Act in response to increasing environmental concerns. In the 1970s and 1980s, in complying with the act, the emphasis was on construction grant programs that built additional interceptors and upgraded wastewater treatment plants. The 1990s saw the enactment of additional initiatives to address sanitary sewer overflows, storm water quality, and combined sewer overflows. Specifically, with respect to CSOs, the U.S. Environmental Protection Agency (EPA) passed the CSO Control Policy in 1994 (EPA, 1994).

The CSO control policy contains provisions for developing appropriate, site-specific permit requirements for all wet weather CSOs. These permit requirements are administered by the state of Michigan through the NPDES permitting program (MDEQ, 1994). The policy requires that a community with CSOs shall i) characterize their combined sewer system, ii) demonstrate implementation of nine minimum controls, and iii) develop a long-term CSO control plan. The nine minimum controls are:

1. proper operation and maintenance of the collection system and treatment plant,

2. maximize use of system storage,

3. pretreatment to minimize CSO impacts,

4. maximize flow to the wastewater treatment plant,

5. prohibit dry weather CSOs,

6. control CSO solid and floatable materials,

7. contaminant reduction activities,

8. public notification of CSO occurrences, and

9. measure CSO impacts and control efficacy.

These controls are technology-based actions or measures designed to reduce CSOs and minimize their impacts on receiving water quality. It is the requirement that the public be notified of CSO occurrences (item no. 8) that led to the development of a CSO notification model that is the subject of this chapter. According to the guidance paper for the nine minimum controls (EPA, 1995), the intent of the eighth minimum control, public notification, is to inform the public of the location of CSO outfalls, the actual occurrences of CSOs, the 
possible health and environmental effects of CSOs, and the recreational or commercial activities (e.g. swimming and shellfish harvesting) curtailed as a result of CSOs. As previously mentioned, the City of Detroit is responsible for 77 outfalls that have the potential of discharging combined sewerage during wet weather events. The City needed a way to comply with these permit requirements for these outfalls.

\subsection{Approach}

The occurrence and time of overflow can be estimated by using a calibrated hydrologic/hydraulic model. The City of Detroit has a hydrologic/hydraulic model known as the Greater Detroit Regional Sewer System (GDRSS) model that has been developed over several years. Recently, the model has been updated with additional detail and calibration (TenBroek et al., 1999) and it has been used in the development of the City of Detroit's long-term CSO control plan (City of Detroit, 1996).

The GDRSS model is based on the EPA SWMM program (Huber and Dickinson, 1988). Both an event model and a continuous model were developed. The event model uses RUNOFF and EXTRAN to simulate specific events and has been used for detailed hydraulic analysis of the collection system. The continuous model uses RUNOFF and TRANSPORT to simulate a long period of rainfall record, typically of the order of several years.

The advantages of using GDRSS to determine the most probable wet weather discharges include:

- The model uses an accepted methodology and framework to determine volume and duration of CSOs. It uses SWMM, which is one of the programs recommended for modeling of combined systems in the guidance paper for monitoring and modeling of combined systems (EPA, 1999).

- The model was specifically developed to determine CSO duration and volume for a variety of storm events.

- GDRSS has been calibrated and validated using flow data from a number of events.

- The level of detail is appropriate; that is, the model was developed with a focus towards prediction of CSOs. It includes all 77 outfalls owned by the City of Detroit.

- The use of the model as an interim reporting method has been approved by MDEQ until the outfalls are equipped with instrumentation for direct monitoring.

- The use of the model is cost effective. 
GDRSS was originally used to estimate annual overflows and the frequency of these overflows based on a rainfall record from a single rain gage for a number of years. For this work, this same model could be used for one month of rainfall at a time from multiple gages to compute amount and duration of these overflow episodes from the overflow locations.

GDRSS does not have an interface, however, that would facilitate the routine use of the model on a monthly basis. Setting up the model input files with monthly rainfall files for multiple gages, running the simulations, and then compiling the results into a format suitable for reporting would be cumbersome. It was desired that an interface be developed to facilitate the development of the CSO Notification Model, which is now described.

\subsection{CSO Notification Model}

The CSO Notification Model specifically refers to an interface that was developed to facilitate the use of GDRSS by DWSD staff. The interface originally was written in Pascal when the interface was first developed in 1995. In 1999, the model was updated to incorporate updates made to GDRSS. These updates included pump drawdown and pump operation, beside general model updates. At the time the model was updated, the interface was rewritten in Visual Basic $^{\text {(8) }}$ to make use of features available in the window environment. The program uses MS Access ${ }^{\text {for }}$ for database management, and Crystal Reports ${ }^{\circledR}$ for generating reports.

The interface consists of three major components:

1. setup of the input files,

2. running the simulations, and

3. compiling the output into report format.

The model requires rainfall data and pump operation data for the time frame being simulated. Due to the size of the tributary area, the area was divided into six regions to provide better spatial resolution of the rainfall, as shown in Figure 20.2. For each region, a primary rain gage and several alternative gages were specified, represented in the figure as triangles, circles, and squares. Rainfall data for these gages are collected by the Southeast Michigan Council of Government (SEMCOG) and posted on the Internet, generally within 4 to 6 months of occurrence. After the precipitation data are downloaded, the interface program reads the file and imports the desired data for the selected gages. If the primary gage is missing data, the program automatically checks the specified alternative gages for data. Unfortunately, the precipitation database does not distinguish whether a gage is missing data due to no precipitation or due to being out of service for repair. 


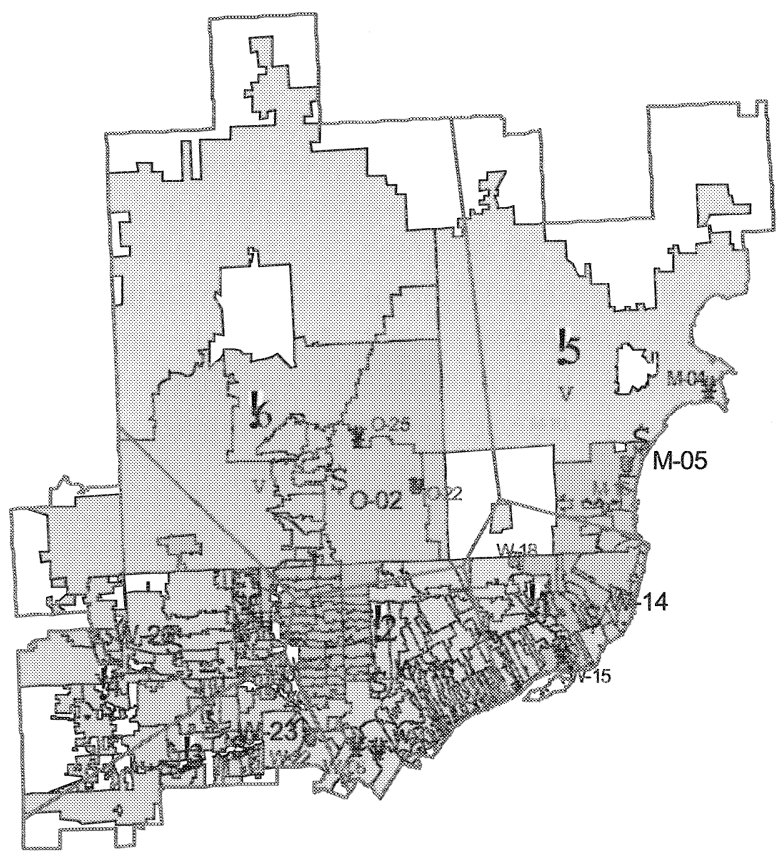

Figure 20.2. Rain gage network.

The program provides several ways to review the data: by daily rain gage totals, by daily region (polygon) totals, and by monthly rain gage totals. The output can be reviewed onscreen in either a graph or table format and printed if desired. The biggest drawback to the rainfall data beyond the documentation is that it is hourly data. A higher resolution would be preferable as the model was developed for use of 15-minute data. However, the ability to import relatively current rainfall data and to have several gages for the area is significant and greatly facilitates the use of GDRSS for this application.

Another input required is pump operation. There are several pumps within the system that are subject to operator control. The user must obtain pump operation records from system controls and scan the records for information on the operation of the pumps. A feature was added to the SWMM code within TRANSPORT to allow the pump operations for three pump stations within the system to be defined for each simulation.

This feature is important, as these pumps do not operate to a defined set of rules. As a result, extra detail is necessary to ensure that the model results are reasonable. In addition, the operation of these three pump stations impacts pumped discharges, which are compared to the model results.

Once the user has completed entering the required data, the program updates the RUNOFF and TRANSPORT input files and initiates the simulation 
in a DOS window. At completion, control is passed back to the interface program and the user can review the results and prepare the report. As with the rainfall data, the results can be reviewed graphically and by tables. These outputs can be prepared for one district or for all districts, and by day or week or month. An example of the model's overflow results in graphical format is shown in Figure 20.3.

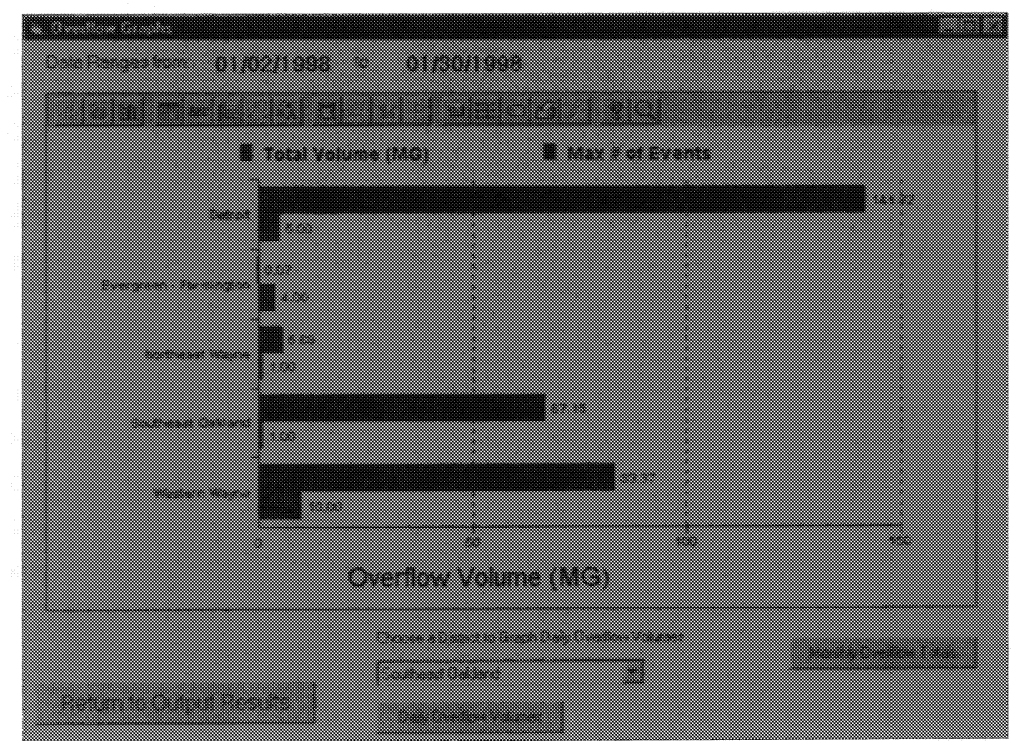

Figure 20.3 Overflow volumes for month of January, 1998.

Results are also provided in tabular format and include the details of the date, hour, duration, and volume of each overflow event predicted. These tables can easily be printed and used in the report submitted to the Michigan State Department of Environmental Quality, in compliance with permit requirements.

The total time estimate for producing a monthly report is estimated to be 70 minutes, as detailed in Table 20.1.

Table 20.1 Time estimate for preparation of monthly CSO Notification Report.

\begin{tabular}{lc}
\hline \multicolumn{1}{c}{ Procedure } & Time (Minutes) \\
\hline Prepare pump operation & 20 \\
Prepare rainfall data & 5 \\
Run simulation & 10 \\
Review results & 25 \\
Prepare report & 10 \\
TOTAL & 70 \\
\hline
\end{tabular}




\subsection{Discussion}

According to the guidance paper for the nine minimum controls (EPA 1995), as a minimum control, public notification actions have no direct effect on reducing overflows and pollutant loads from CSO systems, or on minimizing water quality impacts. Notification, however, will diminish the potential risk of adverse public health effects. It goes on to say that such actions will also increase public awareness and might increase public support for CSO control programs. Because the reporting of CSOs is done on a monthly basis and because the rainfall data available for this use generally lags by 4 to 6 months, the public notification as implemented is a report rather than notification during or immediately following a CSO event. This method was approved by the state as an interim reporting method until an instrumentation project currently under way is completed.

A search for papers or references for experiences of other cities in complying with this requirement of the CSO control policy did not result in any discoveries for comparison. At the CHI 2000 conference, Dr. James noted that the city of Stockholm has a couple of granite obelisks about 5 meters high with a light display showing pollutant loads, in a prominent downtown public park that can be viewed by passing traffic (personal communication). This was described as an example of a city working hard at increasing the public awareness of the impacts of a sewer collection system with overflows on the local environment.

\section{Acknowledgments}

This work was performed by Camp Dresser \& McKee for the Detroit Water $\&$ Sewerage Department (DWSD). The project was a team effort that included both the project team and the client staff.

\section{References}

City of Detroit. 1996. Long-Term CSO Control Plan for the Detroit and Rouge Rivers. Consultant Services Contract: CS-1158, DWSD, Detroit, Michigan.

Huber, W.C. and Dickinson, R.E. 1988. Storm Water Management Model, Version 4: User's Manual. Cooperative Agreement CR-811607. United States Environmental Protection Agency. Athens, Georgia. 569 pp.

Michigan Department of Environmental Quality (MDEQ). 1994. Act 451, Michigan Statues, Part 31. 
TenBroek, M.J., G. Fujita, P. Brink, B.J. Sherman and D. White. 1999. "Detroit Water and Sewerage Department Model Extensions and Project Overview." Journal of Water Management Modeling R204-11. doi: 10.14796/JWMM.R204-11.

U.S. Environmental Protection Agency (EPA). 1994. Combined Sewer Overflow Control Policy. EPA 830-B-94-001, Washington, D.C. April 1994.

U.S. Environmental Protection Agency (EPA). 1995. Combined Sewer Overflows: Guidance for Nine Minimum Controls. EPA 832-B-95-003, Washington, D.C. April 1994.

U.S. Environmental Protection Agency (EPA). 1999. Combined Sewer Overflows, Guidance for Monitoring and Modeling. EPA 832-B-99-002, January, 1999. 
